\title{
Tribenzopentaphene derivatives with lateral aromatic groups: the effect of the nature and position of substituents on emission properties $\dagger$
}

\author{
Bassam Alameddine, ${ }^{\star a}$ Rajamohanan Sobhana Anju, ${ }^{a}$ Fakhreia Al-Sagheer ${ }^{b}$ and \\ Titus A. Jenny ${ }^{c}$
}

\begin{abstract}
Nine new derivatives of the trapezoidal tribenzopentaphene (TBP) polycyclic aromatic hydrocarbon (PAH) were synthesized via the Suzuki-Miyaura palladium catalyzed cross-coupling reaction. The novel TBP derivatives, which bear various rigid and flexible aromatic groups either at their more accessible $\left(R_{1}\right)$ or congested $\left(R_{2}\right)$ bases, were fully characterized using high resolution mass spectrometry (HR-MS), nuclear magnetic resonance (NMR), UV-Vis absorption and emission spectroscopy. Our investigation reveals that extended conjugation between TBP and the aromatic side groups is possible when the latter are carefully selected and attached at the TBP wide base $\left(R_{1}\right)$, which causes an emission red-shift of the resulting target compounds. On the other hand, emission properties and density functional calculations suggest that attaching side groups at the sterically demanding base position $\left(R_{2}\right)$ induces a pronounced distortion from the planarity of the TBP central core structure.
\end{abstract}

\section{Introduction}

Polycyclic aromatic hydrocarbons (PAHs) have drawn considerable attention owing to their unique optical and electronic properties. ${ }^{1}$ They consist of fused planar conjugated units exhibiting pronounced $\pi-\pi$ stacking interactions, leading to high charge carrier densities along the stacked PAH columns, which make them potential candidates for various applications in molecular electronics. ${ }^{2}$ As a result, pioneering efforts have been made to synthesize a wide variety of PAHs whose dimensions range from single molecules to nanographene polymers. ${ }^{3}$ Recently, various research groups have been able to prepare PAH derivatives doped with heteroatoms ${ }^{4}$ and/or with contorted structures. ${ }^{2 a, 3,5}$ Others have developed alternative facile procedures to synthesize bulky polycyclic aromatics. ${ }^{6}$ Nevertheless, most of the aforementioned PAHs are very extended and highly symmetrical, while studies suggest that altering the size and shape of PAHs more into a one dimensional structure will lower their band-gap, and hence, improve their electron/hole transport mobility. ${ }^{2 d, 7}$ Therefore, we have been interested in synthesizing tapered

\footnotetext{
${ }^{a}$ Department of Mathematics and Natural Sciences, Gulf University for Science and Technology, Kuwait. E-mail: alameddine.b@gust.edu.kw

${ }^{b}$ Chemistry Department, University of Kuwait, Safat, Kuwait

${ }^{c}$ University of Fribourg, Chemin du Musée 9, 1700 Fribourg, Switzerland

$\dagger$ Electronic supplementary information (ESI) available: Synthesis of 5a, HR-MS of 9-11, ${ }^{1} \mathrm{H}-\mathrm{NMR}$ of 9-11, UV absorption-emission spectra of 6-8, computational details and X-ray crystallographic data of 6. CCDC 1486177. For ESI and crystallographic data in CIF or other electronic format see DOI: 10.1039/c6nj02563c
}

polycyclic aromatics, mainly tribenzo[ $f g, i j, r s t]$ pentaphene (TBP), whose trapezoidal structure offers the advantage of its functionalization at various sites, through a convenient synthetic methodology. Nonetheless, the investigation of TBP is scarce and only a handful of derivatives have been prepared: ${ }^{8}$ we have recently described the synthesis of TBP derivatives substituted with aryl amine groups at their $R_{1}$ positions and investigated their hole mobilities. We have also reported the synthesis of di- and tetra-substituted TBP moieties with alkyl chains at various positions $\left(\mathrm{R}_{1}, \mathrm{R}_{3}\right.$, and $\left.\mathrm{R}_{4}\right)$. On the other hand, Huang et al. revealed the synthesis of di- and hexa-substituted TBP derivatives with alkoxy groups at the $\mathrm{R}_{1}, \mathrm{R}_{3}$, and $\mathrm{R}_{4}$ positions. It should be noted that, to our knowledge, TBP derivatives substituted at the narrow base $\left(R_{2}\right)$ have not been reported before (Fig. 1). Therefore, the design and development of new TBP-based derivatives became of crucial interest in order to study the effect of the nature and position of the substituents on the properties of the target

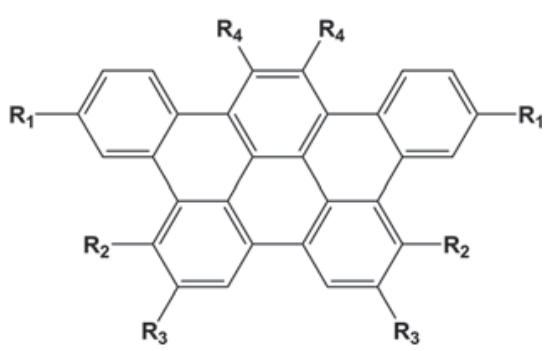

Fig. 1 Structure of tribenzopentaphene showing the four versatile substitution sites. 
molecule. Herein, we report the systematic synthesis and structural characterization of a family of tribenzo $[f g, i j, r s t]$ pentaphene compounds bearing various aromatic side groups at two different positions, i.e. at the more open $\left(\mathrm{R}_{1}\right)$ or the sterically hindered $\left(\mathrm{R}_{2}\right)$ positions. The optical properties of these compounds are discussed based on the characteristics of their UV-Vis absorption and emission spectra, which are correlated with density functional calculations.

\section{Results and discussion}

Scheme 1 summarizes our initial strategy to synthesize the target compounds, which consisted of preparing the two dibrominated derivatives of 1,4-diphenyltriphenylene $\mathbf{4 a , b}$. Cross-coupling of the latter with the heterocyclic aromatic side groups would afford synthons $\mathbf{5 a , b}$ before their cyclodehydrogenation into the fully aromatic molecules. Hence, the synthons 1,3-bis(4-bromophenyl)$2 H$-cyclopenta[l]phenanthren-2-one $3 \mathrm{a}$ and 5,10-dibromo-1,3diphenyl-2H-cyclopenta[ [] phenanthren-2-one $3 \mathbf{b}$ were made through a double Knoevenagel condensation reaction. ${ }^{9}$ The two compounds were isolated as yellow solids from the reaction of $2 \mathbf{a}$ and $\mathbf{1} \mathbf{b}^{\mathbf{1 0}}$ to make $3 \mathbf{a}$ whereas synthon $\mathbf{3 b}$ was obtained from the reaction of $\mathbf{2} \mathbf{b}^{11}$ and 1a. The [4+2] Diels-Alder cycloaddition reaction of $\mathbf{3 a} \mathbf{a} \mathbf{b}$

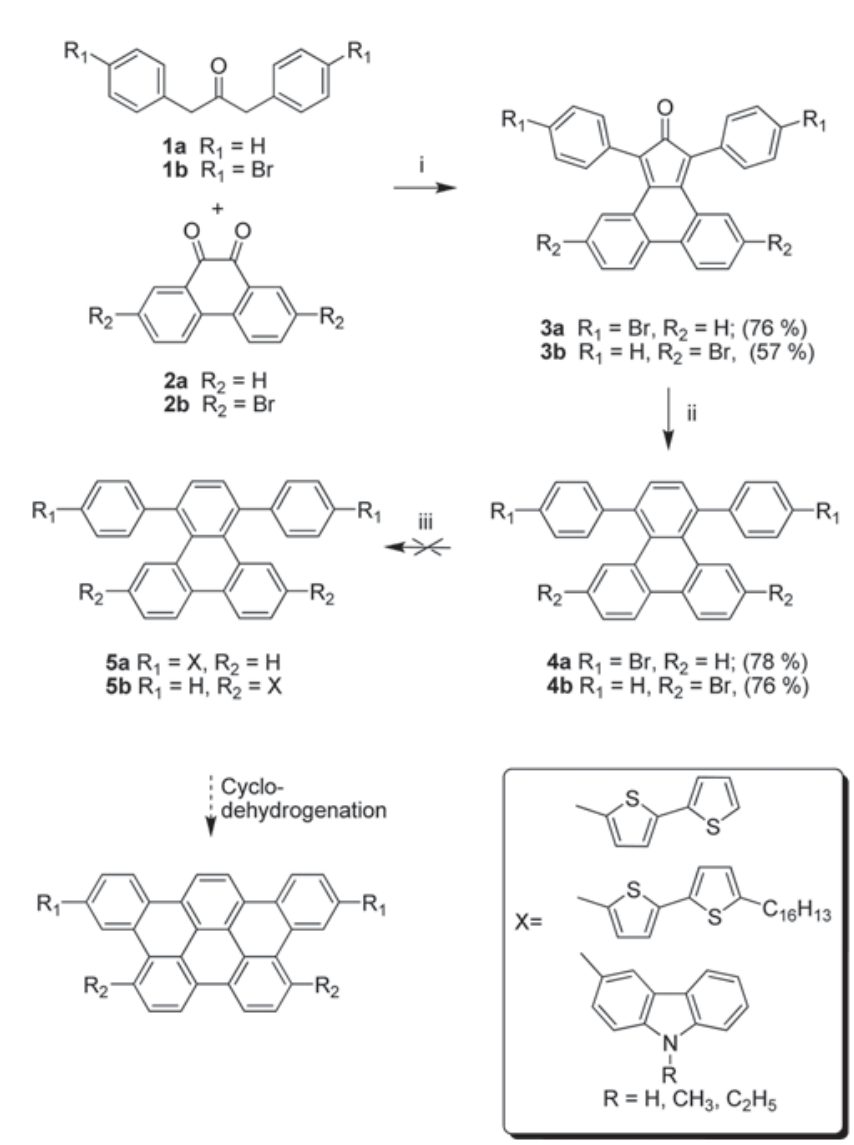

Scheme 1 Synthesis of diphenyltriphenylene derivatives. Reagents and conditions: (i) $\mathrm{KOH}$, methanol, reflux, $4 \mathrm{~h}$, (ii) phenylvinyl sulfoxide, toluene, reflux, $24 \mathrm{~h}$, (iii) a: $\mathrm{Pd}\left(\mathrm{PPh}_{3}\right)_{4}, \mathrm{~K}_{2} \mathrm{CO}_{3}$, boronic ester, toluene $/ \mathrm{H}_{2} \mathrm{O}$, reflux, $96 \mathrm{~h} ; \mathrm{b}:\left[\mathrm{Pd}_{2}(\mathrm{dba})_{3}\right], \mathrm{K}_{3} \mathrm{PO}_{4}$, Sphos, boronic ester, toluene/toluene-butanol $(1: 1) /$ toluene $-\mathrm{H}_{2} \mathrm{O}(10: 1)$, reflux, $96 \mathrm{~h}$. with the acetylene equivalent phenylvinyl sulfoxide in refluxing toluene $^{12}$ affords $\mathbf{4 a , b}$ in good yields (78\% and 76\%, respectively).

Unexpectedly, most of the trials to introduce various aromatic heterocycles onto the respective positions 1,4- and 6,11- of $4 a$ and $\mathbf{4 b}$ (Scheme 1) failed. The Suzuki cross-coupling reactions were performed using either the classical catalytic system ${ }^{13}$ or the more efficient one utilized to couple heterocyclic boronic acids/esters. ${ }^{14}$ It is worthwhile to note that the starting materials were always recovered even after long reaction times and harsh conditions. A notable exception though is the coupling reaction of $4 \mathbf{a}$ with 5'-hexyl-2,2'-bithiophene-5-boronic acid pinacol ester using $\mathrm{Pd}_{2}(\mathrm{dba})_{3} /$ Sphos. Interestingly, the formation of small amounts $(<10 \%)$ of the desired compound was noted after four days of reaction. The unsuccessful attempts to make the Suzuki cross-coupling products $\mathbf{5 a}, \mathbf{b}$ could be attributed to the low reactivity of both the heterocyclic boronic esters and the dibrominated synthons $\mathbf{4 a , b}$. Single crystal X-ray diffraction analysis of 4 a reveals a distorted triphenylene core that impacts its aromaticity, and thus, decreases its overall reactivity (Fig. S20 in the ESI $\dagger$ ). On the other hand, we presume that the crosscoupling reactions to form $\mathbf{5 b}$ were not feasible due to the additional steric hindrance of the bromine substituents on the bay positions 6 and 11 (i.e. $\mathrm{R}_{2}$ ). This analogy is strongly supported by the optimized 3D geometries of $\mathbf{4 a , b}$ using density functional theory (DFT) calculations at the B3LYP level using the 6-31G* basis set (see the ESI $\dagger$ ).

In order to overcome the abovementioned difficulties encountered to introduce the lateral groups, we have decided to reduce the distortion of the central core through its aromatization first, followed by the introduction of the aromatic substituents. Thus, 1,4-diphenyltriphenylene synthons $\mathbf{4 a}$, b were fully aromatized through the Scholl cyclodehydrogenation reaction using iron(III) chloride in nitromethane, ${ }^{15}$ which yields the dibrominated TBP derivatives 6 and 8, respectively, whereas synthon 7 was synthesized using a method reported elsewhere ${ }^{8 a}$ (Scheme 2). The dibrominated TBP synthons 6-8 were purified by a series of precipitation followed by Soxhlet extraction. The structures and purities of the latter compounds were confirmed using high resolution mass spectrometry, ${ }^{1} \mathrm{H}$ - and ${ }^{13} \mathrm{C}-\mathrm{NMR}$ spectroscopy. The lateral substitutions via the Suzuki cross-coupling reaction were then possible under optimized reaction conditions, leading to the formation of the desired compounds 9-11. The target compounds underwent additional purification through a series of Soxhlet extractions by washing off the impurities with hexane/ pentane, and diethyl ether for 4 hours each, followed by the extraction of the desired compounds from hot toluene over the course of 24 hours. It is worth noting that the reaction completion required only $2 \mathrm{~mol} \%$ of the palladium catalyst, making it a cost-effective method and minimizing the effort to remove the metal from the final products. The target molecules 9-11 are slightly soluble in common organic solvents such as chloroform, dichloromethane, tetrahydrofuran, and toluene. Hence, even though they could be analysed using ${ }^{1} \mathrm{H}$-NMR spectroscopy, only some could be concentrated enough to record their ${ }^{13} \mathrm{C}-\mathrm{NMR}$ spectra. Consequently, we have utilized a known tool for the characterization of PAH materials with low solubility, and that is 


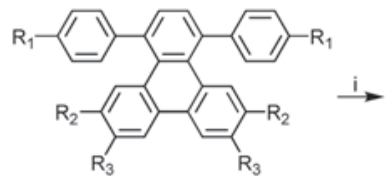

4a $R_{1}=B r, R_{2}=R_{3}=H$ $4 b R_{1}=R_{3}=H, R_{2}=B r$

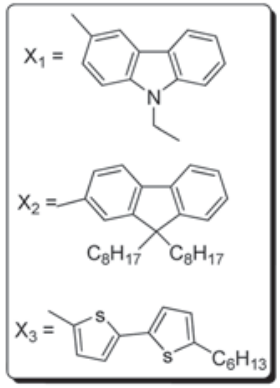

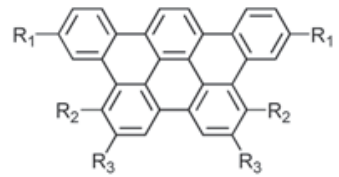

$6 \mathrm{R}_{1}=\mathrm{Br}, \mathrm{R}_{2}=\mathrm{R}_{3}=\mathrm{H}$ $7 \mathrm{R}_{1}=\mathrm{Br}, \mathrm{R}_{2}=\mathrm{H}, \mathrm{R}_{3}=\mathrm{C}_{12} \mathrm{H}_{25} \quad(88 \%)$ $8 \mathrm{R}_{1}=\mathrm{R}_{3}=\mathrm{H}, \mathrm{R}_{2}=\mathrm{Br} \quad(86 \%)$

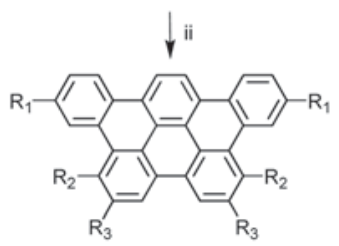

9a $\quad R_{1}=X_{1}, R_{2}=R_{3}=H$ 9b $\quad R_{1}=X_{2}, R_{2}=R_{3}=H$ 9c $\quad R_{1}=X_{3}, R_{2}=R_{3}=H$ 10a $R_{1}=X_{1}, R_{2}=H, R_{3}=C_{12} H_{25}$ 10b $R_{1}=X_{2}, R_{2}=H, R_{3}=C_{12} H_{25}$ 10c $R_{1}=X_{3}, R_{2}=H, R_{3}=C_{12} H_{25}$ 11a $R_{1}=X_{3}, R_{2}=H, R_{2}=X_{1}$ $11 a R_{1}=R_{3}=H, R_{2}=X_{1}$
$11 b R_{1}=R_{3}=H, R_{2}=X_{2}$ 11c $R_{1}=R_{3}=H, R_{2}=X_{3}$

Scheme 2 Synthesis of tribenzopentaphene (TBP) derivatives. Reagents and conditions: (i) $\mathrm{FeCl}_{3}, \mathrm{MeNO}_{2}, \mathrm{CH}_{2} \mathrm{Cl}_{2}, 45^{\circ} \mathrm{C}$; (ii) $\left[\mathrm{Pd}_{2}(\mathrm{dba})_{3}\right], \mathrm{K}_{3} \mathrm{PO}_{4}$ Sphos, boronic ester, toluene-butanol $(1: 1), 110^{\circ} \mathrm{C}, 96 \mathrm{~h}$.

high-resolution matrix-assisted laser desorption ionization-time of flight mass spectrometry (HR-MALDI-TOF MS) using trans-2[3-(4-t-butyl-phenyl)-2-methyl-2-propenyilidene]-malononitrile (DCTB) as the matrix. The aforementioned technique reveals the high purity of compounds $\mathbf{9 - 1 1}$ as it could be noticed from the measured isotopic patterns of $\mathbf{9 a , b}$ compared to their respective calculated peaks in Fig. 2 (for the other derivatives see the ESI $\dagger$ ).

The photophysical characteristics of TBP derivatives 9-11 were investigated by means of UV-Vis absorption and emission spectroscopy using toluene as a solvent (Fig. 3). Having absorption-emission data for a set of TBPs in hand allowed us to compare the effect of the substituents' nature and position on their optical properties. The absorption spectra of all the compounds displayed similar features i.e. a strong absorption band at $300-310 \mathrm{~nm}$ and less intense bands at $350-390 \mathrm{~nm}$, which are characteristics of the tribenzopentaphene core. ${ }^{8 a, d}$ It is noteworthy that the absorption bands for TBP derivatives 9-11 exhibit no or only a slight difference when the substituents are either on the wide (i.e. $\mathrm{R}_{1} ; \mathbf{9 - 1 1 a}, \mathbf{b}$ ) or narrow (i.e. $\mathrm{R}_{2} ; \mathbf{9 - 1 1 c}$ ) bases. It should be noted that when carbazole or fluorene derivatives are attached to the more open base $\left(\mathrm{R}_{1}\right)$, the resulting compounds 9-10a,b display the same emission recorded for 3,12-dioctyltribenzopentaphene $(415 \mathrm{~nm}){ }^{8 d}$ This clearly indicates that there is no or very little conjugation between TBP and the lateral fused aromatic groups, which could be explained by a preference for these rigid substituents to adopt a tilted configuration instead of a coplanar arrangement with the TBP core. On the other hand, when the latter is substituted at the same positions $\mathrm{R}_{1}$ by $2,2^{\prime}$-bithiophene (9-10c), a $\sim 35 \mathrm{~nm}$ red shift emission is noticed. This bathochromic shift suggests a better conjugation between TBP and dithiophene whose smaller fivemembered ring and higher number of rotation axes allow for a
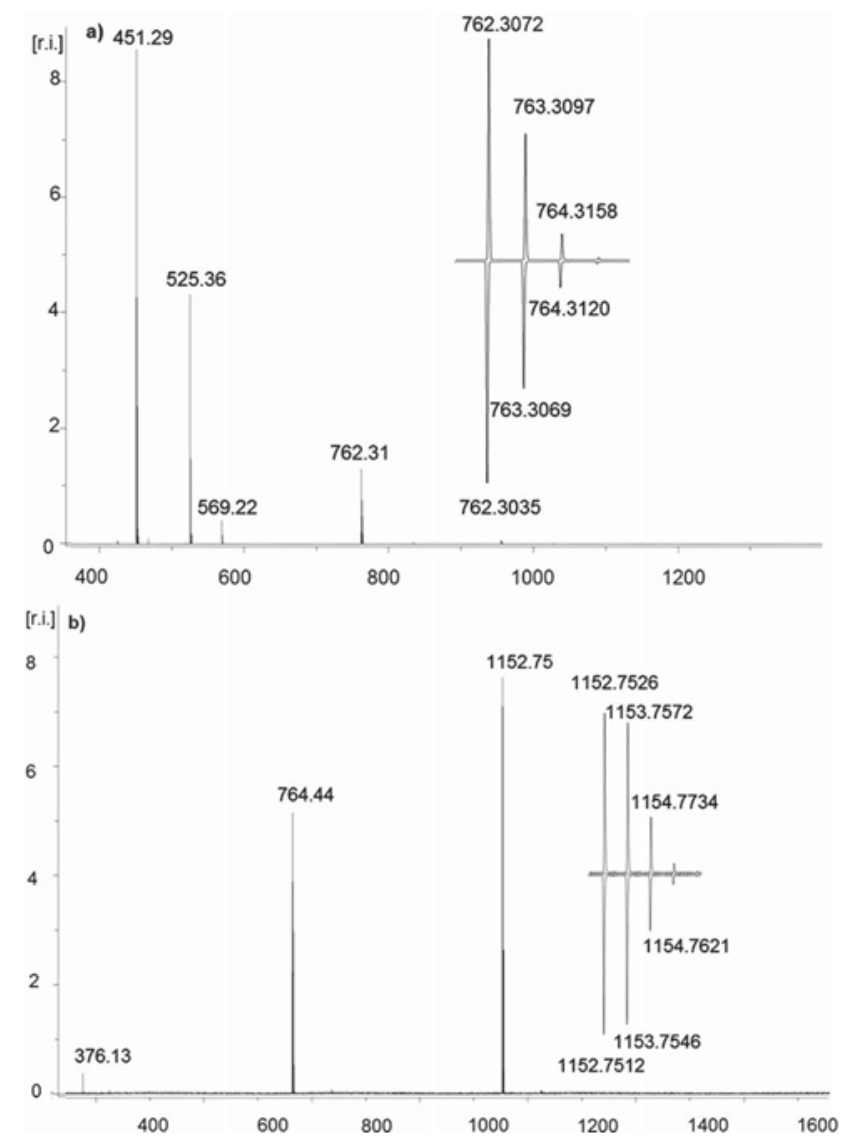

Fig. 2 (a) HR-MALDI-TOF mass spectrum of $9 a$ in DCTB; inset: measured (up) and calculated isotopic pattern (down), calculated for $\mathrm{C}_{58} \mathrm{H}_{38} \mathrm{~N}_{2}{ }^{+\bullet}$. (b) HRMALDI-TOF mass spectrum of $\mathbf{9 b}$ in DCTB; inset: measured (up) and calculated isotopic pattern (down), calculated for $\mathrm{C}_{88} \mathrm{H}_{96}{ }^{+\bullet}$

more pronounced coplanar arrangement with the TBP core when compared to the other two rigid fused aromatic substituents (i.e. carbazole and fluorene). This discloses the importance of the lateral substituent structure and its effect on conjugation.

When carbazole or fluorene groups are substituted at the sterically hindered base $\left(\mathrm{R}_{2}\right)$, the emission spectra of compounds 11a,b portray a $\sim 20 \mathrm{~nm}$ red shift from their respective isomers 9-10a,b. This could be interpreted by a possible better conjugation and/or distortion of the planar TBP core caused by the steric demand of the attached fused aromatic groups. Surprisingly, when $2,2^{\prime}$-bithiophene is doubly attached to the same congested base $\left(\mathrm{R}_{2}\right), 11 \mathrm{c}$ displays a red shift by $\sim 80 \mathrm{~nm}$ as compared to 11a,b and $\sim 65 \mathrm{~nm}$ with respect to its two isomers 9-10c. Unlike all the other emission spectra, the broad structure-less emission spectrum of 11c suggests a possible excited state planarization of the sterically constrained ground state.

In order to get more insight into the TBP structures and their electronic distributions, we carried out density functional calculations with B3LYP at the 6-31G* level basis set for compounds 9 and 11. Optimized structures of the latter (see Table S1 in the ESI $\dagger$ ) confirm our explanation for the emission properties. It is noteworthy that the TBP core retains its planar structure when functionalized at its wide base $\left(\mathrm{R}_{1}\right)$. Moreover, carbazole and 

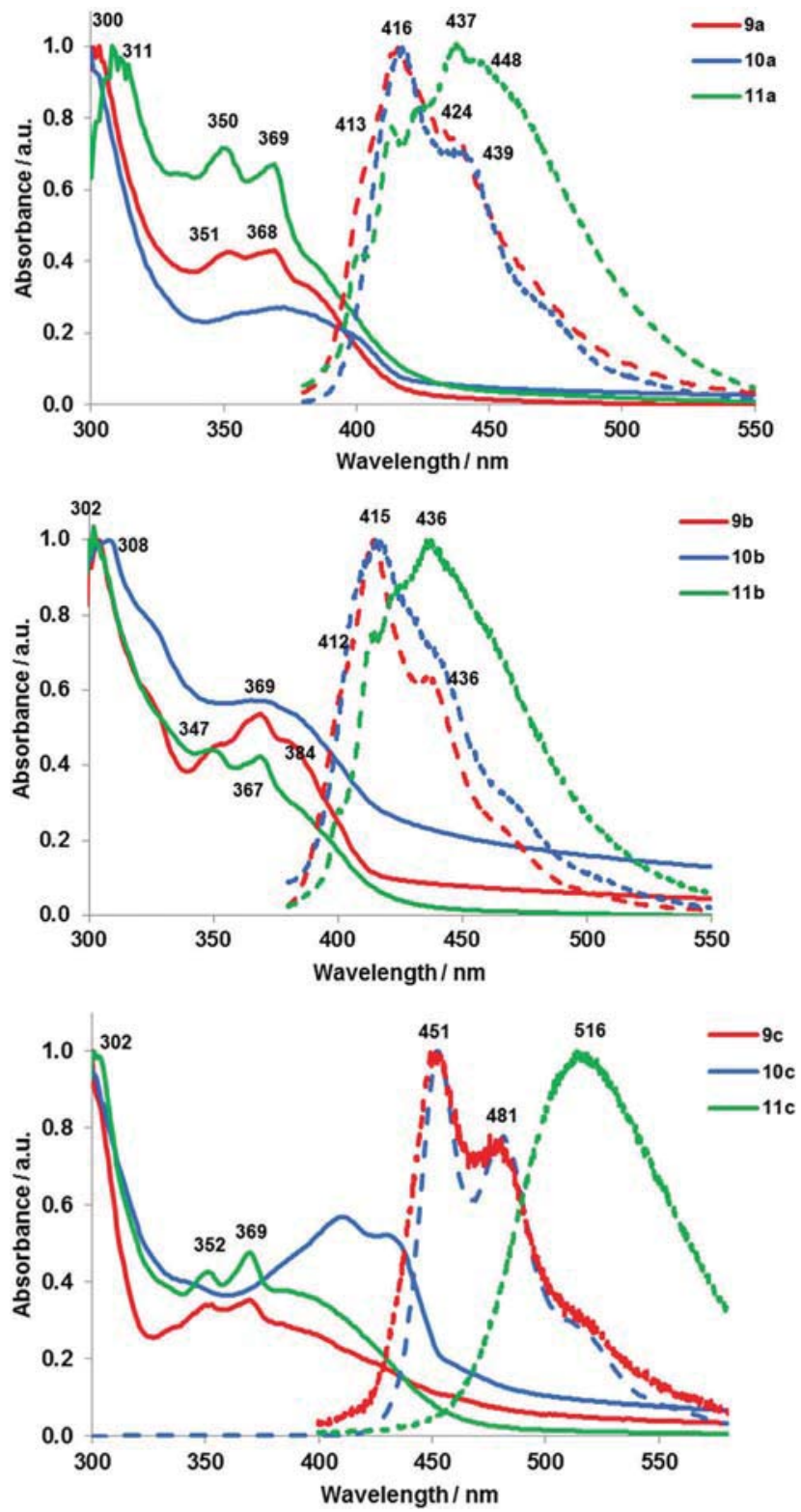

Fig. 3 Normalized absorption and emission spectra for the tribenzopentaphene derivatives $\mathbf{9 - 1 1}$ in toluene. The solid lines represent the absorption spectra and the dotted lines correspond to the emission spectra.

fluorene substituents are out of plane when attached to position $\mathrm{R}_{1}$, which explains the typical emission of 9-10a,b, which resembles very much to a 3,12-dioctyltribenzopentaphene. ${ }^{8 d}$ On the other hand, the red shift observed in 9-10c is expected, because $2,2^{\prime}$-bithiophene lateral groups are more coplanar with the TBP core. Nevertheless, the optimized geometries of TBP substituted at the crowded base $\left(\mathrm{R}_{2}\right)$ reveal that introduction of side groups at the latter position distorts the central aromatic core from planarity and permits the lateral aromatic substituents to be more in-plane with TBP. It is worthwhile to note that according to DFT calculations ( $c f$. ESI $\dagger$ ), distortion of TBP from planarity becomes more pronounced when introducing the 2,2'-bithiophene moiety, which explains the large emission shift discussed previously. Table 1 summarizes some of the relevant
Table 1 Observed and calculated ( $\mathrm{R}=\mathrm{H}$ or $\mathrm{Me}$ ) absorption bands, and HOMO-LUMO orbitals of TBP derivatives 9 and $\mathbf{1 1}$

\begin{tabular}{|c|c|c|c|c|c|c|}
\hline \multirow[b]{2}{*}{ TBP } & \multicolumn{2}{|c|}{$\mathrm{UV}_{\max }(\mathrm{nm})$} & \multirow[b]{2}{*}{$\operatorname{HOMO}^{a}(\mathrm{eV})$} & \multirow[b]{2}{*}{$\operatorname{LUMO}^{a}(\mathrm{eV})$} & \multicolumn{2}{|c|}{ HOMO-LUMO gap (eV) } \\
\hline & Obs. $^{b}$ & Cal. & & & Obs. $^{b}$ & Cal. \\
\hline $9 a$ & 395 & 391 & -4.97 & -1.49 & 3.14 & 3.48 \\
\hline $9 b$ & 396 & 378 & -5.2 & -1.61 & 3.13 & 3.59 \\
\hline $9 c$ & 428 & 434 & -5.06 & -1.92 & 2.90 & 3.14 \\
\hline 11a & 397 & 397 & -4.91 & -1.48 & 3.11 & 3.43 \\
\hline $11 b$ & 398 & 382 & -5.15 & -1.61 & 3.11 & 3.55 \\
\hline 11c & 454 & 439 & -5.05 & -1.93 & 2.73 & 3.12 \\
\hline
\end{tabular}

entries of the experimental and calculated results, where the computed maximum absorption bands are in good agreement with the observed ones. Furthermore, the $0 \rightarrow 0$ transition bands obtained from the absorption-emission spectra (Fig. 3) were found to be $\sim 396 \mathrm{~nm}$ for target compounds 9-11a,b whereas that of 9-11c are detected at 428, 442, and $455 \mathrm{~nm}$, respectively. These values corroborate the computed HOMOLUMO band gaps.

\section{Conclusions}

A systematic approach has been developed to synthesize a library of doubly substituted tribenzopentaphene compounds bearing various aromatic groups at their wide and narrow bases. In addition, this study has explored the optical properties of TBP derivatives showing the crucial effect upon changing the position and nature of the lateral substituents. Therefore, the emission of TBP can be tuned by attaching at its wide base aromatic side groups whose smaller ring size and free rotation axes allow for a better conjugation with the TBP core. The same lateral aromatic substituents were found to induce a distortion of the TBP core when introduced to its congested base leading to a pronounced emission red-shift. Computational calculations further support the observed reactivity and physical properties of the target compounds. This work paves the way for producing customized TBP derivatives with desirable structural modifications for applications in optical and electronic devices.

\section{Experimental section}

\section{General considerations and methods}

All chemicals were used without further purification as purchased from Aldrich, Merck, Riedel-de-Haën, and Fluorochem unless otherwise notified. All the reactions were done under a protective atmosphere using dry nitrogen or argon. The solvents, namely dichloromethane, ether, pentane, 1-butanol, methanol, hexane and toluene, were dried, deoxygenated, and bubbled with argon gas for 30 minutes. Column chromatography was carried out with silica gel 60, 0.04-0.06, from Merck or Brunschwig. Thin layer chromatography was performed on aluminum sheets coated with silica gel 60 F254 and revealed using a UV lamp. Single crystal data collection was done on a Rigaku R-AXIS RAPID II diffractometer using filtered 
Mo-K $\alpha$ radiation. The structure was solved by a direct method using CrystalStructure crystallographic software package except for refinement, which was performed using SHELXL-97. The non-hydrogen atoms were refined anisotropically. Hydrogen atoms were refined using the riding model. UV-Vis spectra were recorded on a VWR UV1600PC spectrophotometer. Photoluminescence spectra were recorded on an Agilent G9800 Cary Eclipse Fluorescence spectrophotometer. Mass spectra were recorded on the following spectrometers: EI spectra were recorded on a HP5988A Quadrupole spectrometer and MALDITOF spectra were recorded on a FT/ICR Bruker 4.7 T BioApex II spectrometer. All MALDI spectra used DCTB as a matrix with a $337 \mathrm{~nm}$ nitrogen laser. NMR spectra were recorded on a Bruker Avance DPX $360 \mathrm{MHz}\left({ }^{1} \mathrm{H}\right.$ : $360 \mathrm{MHz},{ }^{13} \mathrm{C}$ : $\left.90.55 \mathrm{MHz}\right)$ or Bruker Avance III $500 \mathrm{MHz}\left({ }^{1} \mathrm{H}\right.$ : $\left.500 \mathrm{MHz},{ }^{13} \mathrm{C}: 126 \mathrm{MHz}\right)$ spectrometer using $\mathrm{CDCl}_{3}$ or $\mathrm{CD}_{2} \mathrm{Cl}_{2}$ as a solvent and the chemical shifts $(\delta)$ are given in ppm, coupling constants $(J)$ in $\mathrm{Hz}$, and are all referred to tetramethylsilane (TMS).

\section{Synthesis}

1,3-Bis(4-bromophenyl)-2H-cyclopenta[ $l]$ phenanthren-2-one, 3a. $\mathrm{KOH}(0.13 \mathrm{~g}$ in $1 \mathrm{~mL}$ methanol) was added in a dropwise manner to a solution of 1,3-bis(4-bromophenyl)propan-2-one, 1 b (1.8 g, $4.9 \mathrm{mmol})$ and phenanthrene-9,10-dione, $2 \mathrm{a}(1.00 \mathrm{~g}, 4.8 \mathrm{mmol})$ in methanol $(40 \mathrm{~mL})$. The mixture was then refluxed for $2 \mathrm{~h}$ and cooled to room temperature. The green precipitate was filtered using Millipore and washed with methanol yielding $2.0 \mathrm{~g}$ (76\%) of the desired compound $\mathbf{3 b}$ as a green solid.

${ }^{1} \mathrm{H}-\mathrm{NMR}:\left(360 \mathrm{MHz}, \mathrm{CDCl}_{3}\right): \delta_{\mathrm{TMS}} 7.83(\mathrm{~d}, 2 \mathrm{H}, \mathrm{ArH}), 7.58$ $7.57(\mathrm{~m}, 4 \mathrm{H}, \mathrm{ArH}), 7.55$ (d, 4H, ArH), $7.30(\mathrm{t}, 2 \mathrm{H}, \operatorname{ArH}), 7.29$ (br., 2H, ArH), 6.99 (br., $2 \mathrm{H}, \mathrm{ArH}$ ); EI-MS = $m / z$ (\% int): 538.100 $\left([\mathrm{M}-\mathrm{H}]^{\bullet+}, 100\right),\left(\mathrm{m} / z\right.$ calcd for $\mathrm{C}_{29} \mathrm{H}_{16} \mathrm{Br}_{2} \mathrm{O}^{+}$: 539.954).

5,10-Dibromo-1,3-diphenyl-2H-cyclopenta[l]phenanthren-2-one, 3b. $\mathrm{KOH}(0.26 \mathrm{~g}$ in $2 \mathrm{~mL}$ methanol) was added in a dropwise manner to a solution of 2,7-dibromophenanthrene-9,10-dione, $2 \mathbf{b}$ (3.66 g, $10 \mathrm{mmol})$ and 1,3-diphenylpropan-2-one, 1a (2.14 g, $10 \mathrm{mmol})$ in methanol $(80 \mathrm{~mL})$. The mixture was then refluxed for $2 \mathrm{~h}$ and cooled to room temperature. The green precipitate was filtered using Millipore and washed with methanol yielding $3.1 \mathrm{~g}$ $(57 \%)$ of the desired compound $3 \mathbf{a}$ as a green solid.

${ }^{1} \mathrm{H}-\mathrm{NMR}:\left(360 \mathrm{MHz}, \mathrm{CDCl}_{3}\right.$ ): $\delta_{\mathrm{TMS}} 7.62$ (br., $\left.2 \mathrm{H}, \mathrm{ArH}\right), 7.60$ (t, 2H, ArH), 7.54 (d, 1H, ArH), 7.47 (d, 2H, ArH), 7.45 (d, 2H, $\operatorname{ArH}), 7.44$ (d, 1H, ArH), 7.42 (m, 2H, ArH), 7.39 (m, 4H, ArH); EI-MS $=m / z$ (\% int): $540.100\left([\mathrm{M}+\mathrm{H}]^{\bullet+}, 100\right),(m / z$ calcd for $\left.\mathrm{C}_{29} \mathrm{H}_{16} \mathrm{Br}_{2} \mathrm{O}: 539.954\right)$.

1,4-Bis(4-bromophenyl)triphenylene, 4a. 1,3-Bis(4-bromophenyl)$2 H$-cyclopenta[ $[$ phenanthren-2-one, 3a $(1.00 \mathrm{~g}, 1.85 \mathrm{mmol})$ and phenylvinylsulfoxide $(0.29 \mathrm{~g}, 1.90 \mathrm{mmol})$ were refluxed under argon in dry toluene $(15 \mathrm{~mL})$ for $24 \mathrm{~h}$. After cooling to room temperature, the solvent was evaporated and the crude product was concentrated, precipitated using hexane, followed by Millipore filtration affording the desired product as a yellow solid $(0.780 \mathrm{~g}, 78 \%)$.

${ }^{1} \mathrm{H}-\mathrm{NMR}:\left(360 \mathrm{MHz}, \mathrm{CDCl}_{3}\right.$ ): $\delta_{\mathrm{TMS}} 8.83(\mathrm{~d}, 2 \mathrm{H}, \mathrm{ArH}), 7.71$ (p, 2H, ArH), 7.52 (d, 4H, ArH), 7.35 (m, 4H, ArH), 7.25 (br., 2H, ArH), 7.12 (br., 4H, ArH); EI-MS $=m / z$ (\% int): $538.920\left([\mathrm{M}+\mathrm{H}]^{\bullet+}, 100\right),\left(\mathrm{m} / z\right.$ calcd for $\mathrm{C}_{30} \mathrm{H}_{18} \mathrm{Br}_{2}{ }^{+}$: 537.975).
6,11-Dibromo-1,4-diphenyltriphenylene, 4b. 5,10-Dibromo1,3-diphenyl-2H-cyclopenta[l]phenanthren-2-one, $3 \mathbf{b}$ (1.08 g, $2 \mathrm{mmol})$ and phenylvinylsulfoxide $(0.35 \mathrm{~g}, 2.3 \mathrm{mmol})$ were refluxed under argon in dry toluene $(15 \mathrm{~mL})$ for $24 \mathrm{~h}$. After cooling to room temperature, the solvent was evaporated and the crude product was concentrated, precipitated using hexane followed by Millipore filtration affording the desired product as a yellow solid (820 $\mathrm{mg}, 76 \%)$.

${ }^{1} \mathrm{H}-\mathrm{NMR}:\left(360 \mathrm{MHz}, \mathrm{CDCl}_{3}\right.$ ): $\delta_{\text {TMS }} 8.23(\mathrm{~d}, 2 \mathrm{H}, \mathrm{ArH}), 7.77$ (d, 2H, ArH), 7.58 (br., 2H, ArH), 7.53 (d, 1H, ArH), 7.52 (d, 1H, ArH), 7.46 (br., $10 \mathrm{H}, \mathrm{ArH})$; EI-MS = $m / z$ (\% int): $537.900\left(\mathrm{M}^{\bullet+}\right.$, $100),\left(\mathrm{m} / z\right.$ calcd for $\left.\mathrm{C}_{30} \mathrm{H}_{18} \mathrm{Br}_{2}^{+}: 537.975\right)$.

(3,12-Dibromotribenzo[fg, $\boldsymbol{i j}, r s t]$ pentaphene), 6. To a solution of 1,4-bis(4-bromophenyl)triphenylene (0.506 g, $0.94 \mathrm{mmol})$ in dichloromethane $(60 \mathrm{~mL})$ and purged with argon for $30 \mathrm{~min}$, was added a degassed solution of $\mathrm{FeCl}_{3}(3.04 \mathrm{~g}, 18.8 \mathrm{mmol}, 20$ eq.) in $\mathrm{CH}_{3} \mathrm{NO}_{2}(10 \mathrm{~mL})$ over $10 \mathrm{~min}$. The reaction medium was heated to $45{ }^{\circ} \mathrm{C}$ and bubbled with argon throughout the entire reaction time $(6 \mathrm{~h})$ where the colour turned from light yellow to darkbrown. After the evaporation of DCM, $150 \mathrm{~mL}$ of a $1 \mathrm{M} \mathrm{HCl}$ solution was added to the residue and the resulting green suspension was sonicated for $30 \mathrm{~min}$ and filtered using Millipore. The precipitate was washed several times with water and pentane. Soxhlet extraction of the resulting brown solid was then carried out with pentane $(4 \mathrm{~h})$ and diethyl ether $(4 \mathrm{~h})$. The remaining solid was extracted with hot toluene for $24 \mathrm{~h}$ yielding $450 \mathrm{mg}$ (89\%) of the desired compound 6 as a pale yellow powder.

${ }^{1} \mathrm{H}-\mathrm{NMR}:\left(500 \mathrm{MHz}, \mathrm{CD}_{2} \mathrm{Cl}_{2}\right): \delta_{\mathrm{TMS}} 8.87-8.79(\mathrm{~m}, 2 \mathrm{H}, \mathrm{ArH})$, 7.79 (t, 2H, ArH), 7.72 (d, 2H, ArH), 7.61-7.59 (d, 2H, ArH), 7.48 (t, 2H, ArH), 7.44 (m, 2H, ArH), 7.41 (br., 2H, ArH); ${ }^{13} \mathrm{C}-\mathrm{NMR}$ : (90.55 MHz, $\mathrm{CD}_{2} \mathrm{Cl}_{2}$ ): $\delta_{\text {TMS }} 132.82$ (2C, $\left.\mathrm{Ar}\right), 132.51$ (2C, $\mathrm{Ar}$ ), 132.01 (4C, Ar), 128.90 (4C, Ar), 128.17 (2C, Ar), 127.73-127.52 (6C, Ar), 126.80 (2C, Ar), 125.61 (2C, Ar), 124.27-123.77 (6C, Ar); MALDI-HRMS (DCTB): $\mathrm{m} / z$ (\% int): $533.9484\left(\mathrm{M}^{\bullet+}, 100 \%\right),(\mathrm{m} / \mathrm{z}$ calculated for $\mathrm{C}_{30} \mathrm{H}_{14} \mathrm{Br}_{2}^{+}$: 533.9436); UV/VIS: (toluene, $10^{-5} \mathrm{M}$ ), $\lambda_{\text {max }}[\mathrm{nm}]=309,357,375$.

(3,12-Dibromotribenzo[fg, $i j, r s t]$ pentaphene), 8. A solution of 1,4-bis(4-bromophenyl)triphenylene (506 $\mathrm{mg}, 0.94 \mathrm{mmol}$ ) in dichloromethane $(60 \mathrm{~mL})$ was purged with argon for $30 \mathrm{~min}$, and subsequently a degassed solution of $\mathrm{FeCl}_{3}(3.04 \mathrm{~g}$, $18.8 \mathrm{mmol}, 20$ eq.) in $\mathrm{CH}_{3} \mathrm{NO}_{2}(10 \mathrm{~mL})$ was added over $10 \mathrm{~min}$. The reaction medium was heated to $45{ }^{\circ} \mathrm{C}$ and bubbled with argon throughout the entire reaction time $(6 \mathrm{~h})$, during which the color turned from light yellow to dark-brown. After evaporation of DCM, $150 \mathrm{~mL}$ of a $1 \mathrm{M} \mathrm{HCl}$ solution was added to the residue and the resulting green suspension was sonicated for $30 \mathrm{~min}$ and filtered using Millipore. The precipitate was washed several times with water and pentane. Soxhlet extraction of the resulting brown solid was then carried out with pentane $(4 \mathrm{~h})$ and diethyl ether $(4 \mathrm{~h})$. The remaining solid was extracted with hot toluene during $24 \mathrm{~h}$, yielding $434 \mathrm{mg}$ (86\%) of the desired compound 8 as a pale yellow powder.

${ }^{1} \mathrm{H}-\mathrm{NMR}:\left(500 \mathrm{MHz}, \mathrm{CD}_{2} \mathrm{Cl}_{2}\right.$ ): $\delta_{\text {TMS }} 8.68$ (d, 2H, ArH), 7,87 (d, 2H, ArH), 7.79 (d, 2H, ArH), 7.68 (d, 2H, ArH), 7.57 (m, 2H, ArH), $7.46(\mathrm{~m}, 2 \mathrm{H}, \operatorname{ArH}), 7.37(\mathrm{t}, 2 \mathrm{H}, \operatorname{ArH})$; MALDI-HRMS (DCTB): $m / z$ (\% int): $533.9462\left(\mathbf{M}^{\bullet+}, 100 \%\right),(m / z$ calculated for 
$\mathrm{C}_{30} \mathrm{H}_{14} \mathrm{Br}_{2}^{+}$: 533.9436); UV/VIS: (toluene, $10^{-5} \mathrm{M}$ ), $\lambda_{\max }[\mathrm{nm}]=$ 303, 357, 375 .

3,12-Bis(9-ethyl-9H-carbazol-2-

yl)tribenzo[fg,ij,rst $]$ pentaphene, 9a $(\operatorname{method} \mathrm{A})$. A Schlenck tube was charged with 3,12-dibromotribenzo[fg,ij,rst $]$ pentaphene, 6 (250 mg, $0.47 \mathrm{mmol}$ ), 9-ethyl-9H-carbazole-3-boronicacid pinacolester (664 mg, $2.06 \mathrm{mmol}$ ), tris(dibenzylideneacetone)dipalladium (0.043 g, $\left.4.7 \times 10^{-2} \mathrm{mmol}\right)$, Sphos (38 mg, $\left.9.4 \times 10^{-2} \mathrm{mmol}\right)$, and $\mathrm{K}_{3} \mathrm{PO}_{4}(440 \mathrm{mg}, 2.068 \mathrm{mmol})$ in $15 \mathrm{~mL}$ of a degassed $1: 1$ mixture of toluene and 1-butanol. The reaction was refluxed under argon for 4 days. The solvent was evaporated under a vacuum and the resulting black mixture was extracted with dichloromethane $(\times 3)$ from a saturated aqueous solution of $\mathrm{NaHCO}_{3}$. The combined organic layer was washed with $\mathrm{H}_{2} \mathrm{O}$, concentrated, precipitated using hexane followed by Millipore filtration. Soxhlet extraction of the resulting brown precipitate was then carried out with hexane $(4 \mathrm{~h})$ and diethyl ether $(4 \mathrm{~h})$. The remaining solid was extracted with hot toluene during $24 \mathrm{~h}$ yielding $185 \mathrm{mg}$ (51\%) of the desired compound as an orange solid.

${ }^{1} \mathrm{H}-\mathrm{NMR}:\left(360 \mathrm{MHz}, \mathrm{CDCl}_{3}\right.$ ): $\delta_{\mathrm{TMS}} 9.22$ (br., 2H, ArH), 9.07 (br., 2H, ArH), 8.95 (d, 4H, ArH), 8.13 (t, 6H, ArH), 7.78 (br., 6H, ArH), 7.48-7.36 (br., 8H, ArH), 4.46 (br., $4 \mathrm{H}, \mathrm{CH}_{2}-\mathrm{CH}_{3}$ ), 1.27 (t, $6 \mathrm{H}, \mathrm{CH}_{2}-\mathrm{CH}_{3}$ ); MALDI-HRMS (DCTB): $\mathrm{m} / z$ (\% int): 762.3072 $\left(\mathrm{M}^{\bullet+}, 100 \%\right),\left(\mathrm{m} / z\right.$ calculated for $\mathrm{C}_{58} \mathrm{H}_{38} \mathrm{~N}_{2}$ 872.3030); UV/VIS: (toluene, $10^{-5} \mathrm{M}$ ), $\lambda_{\max }[\mathrm{nm}]=300,367,382$.

(9,9-Dioctyl-9H-fluoren-2-yl)-12-(9,9-dioctyl-9H-fluoren-3-yl)triben$\mathrm{zo}[\boldsymbol{f g}, \boldsymbol{i j}, \boldsymbol{r s t}]$ pentaphene, $9 \mathrm{~b}$. 9b was prepared according to "method A" using 3,12-dibromotribenzo[fg,ij,rst $]$ pentaphene, 6 (150 mg, $0.28 \mathrm{mmol}$ ), 2-(9,9-dioctyl-9H-fluoren-2-yl)-4,4,5,5tetramethyl-1,3,2-dioxaborolane $(640 \mathrm{mg}, 1.232 \mathrm{mmol})$, tris(dibenzylideneacetone)dipalladium $\left(26 \mathrm{mg}, 2.8 \times 10^{-2} \mathrm{mmol}\right.$ ), Sphos (23 mg, $\left.5.6 \times 10^{-2} \mathrm{mmol}\right)$, and $\mathrm{K}_{3} \mathrm{PO}_{4}(260 \mathrm{mg}, 1.23 \mathrm{mmol})$ in $15 \mathrm{~mL}$ of a degassed 1:1 mixture of toluene and 1-butanol. The reaction followed by a work up yielded $\mathbf{9 b}$ as a orange solid (230 mg, 71\%).

${ }^{1} \mathrm{H}-\mathrm{NMR}:\left(500 \mathrm{MHz}, \mathrm{CD}_{2} \mathrm{Cl}_{2}\right)$ : $\delta_{\text {TMS }}$ 9.11-9.07 (br., $\left.2 \mathrm{H}, \mathrm{ArH}\right)$, 9.03-8.75 (br., 2H, ArH), 8.92 (t, 2H, ArH), 8.87 (d, 1H, ArH), 8.83 (d, 1H, ArH), 8.08 (p, 2H, ArH), 7.90 (br., 2H, ArH), 7.82 (d, 2H, ArH), 7.76 (br., 2H, ArH), 7.44-7.01 (br., 12H, ArH), 2.182.11 (br., $\left.4 \mathrm{H}, A l k-\mathrm{C}_{8} \mathrm{H}_{17}\right), 1.58$ (br., $\left.10 \mathrm{H}, A l k-\mathrm{C}_{8} \mathrm{H}_{17}\right), 1.26(\mathrm{~s}, 16 \mathrm{H}$, Alk- $\mathrm{C}_{8} \mathrm{H}_{17}$ ), 1.12 (br., 26H, Alk- $\mathrm{C}_{8} \mathrm{H}_{17}$ ), 0.84 (br., $12 \mathrm{H}, \mathrm{CH}_{3}-$ $\left.\mathrm{C}_{7} \mathrm{H}_{14}\right) ;{ }^{13} \mathrm{C}-\mathrm{NMR}$ : (90.55 MHz, $\mathrm{CD}_{2} \mathrm{Cl}_{2}$ ): $\delta_{\text {TMS }} 152.26$ (2C, $\mathrm{Ar}$ ), 151.68 (2C, Ar), 141.39 (2C, Ar), 141.29 (2C, Ar), 140.37 (2C, Ar), 130.71-130.27 (6C, Ar), 129.49 (2C, Ar), 128.96 (2C, Ar), 128.20126.79 (12C, Ar), 125.10 (2C, Ar), 124.81 (2C, Ar), 124.25 (2C, Ar), 124.17 (2C, Ar), 123.90 (2C, Ar), 123.81 (2C, Ar), 123.58 (2C, Ar), 122.42-122.17 (4C, Ar), 121.60 (2C, Ar), 120.69 (2C, Ar), 120.36 (2C, Ar), 40.94 (2C, Ar), 32.35 (2C, Ar), 30.61 (4C, Ar), 30.25 (4C, $\mathrm{Ar}$ ), 29.85 (4C, Ar), 29.81 (4C, Ar), 24.52 (4C, Ar), 24.52 (4C, Ar), 23.16 (4C, Ar); MALDI-HRMS (DCTB): $m / z$ (\% int): 1152.7526 $\left(\mathrm{M}^{\bullet+}, 100 \%\right),\left(\mathrm{m} / \mathrm{z}\right.$ calculated for $\mathrm{C}_{88} \mathrm{H}_{96}$ 1152.7512); UV/VIS: (toluene, $10^{-5} \mathrm{M}$ ), $\lambda_{\max }[\mathrm{nm}]=303,350,367,384$.

3,12-Bis $\left(5^{\prime}\right.$-hexyl-2,2' -bithiophen-5-yl)tribenzo[ $\left.f g, i j, r s t\right]$ pentaphene, 9c. 9c was prepared according to "method A" using 3,12-dibromotribenzo[ $f g, i j, r s t]$ pentaphene, 6 (150 mg, $0.28 \mathrm{mmol}$ ),
5'-Hexyl-2,2'-bithiophene-5-boronicacid pinacolester (464 mg, $1.232 \mathrm{mmol})$, tris(dibenzylideneacetone)dipalladium $(0.026 \mathrm{~g}$, $2.8 \times 10^{-2} \mathrm{mmol}$ ), Sphos ( $23 \mathrm{mg}, 5.6 \times 10^{-2} \mathrm{mmol}$ ), and $\mathrm{K}_{3} \mathrm{PO}_{4}$ $(260 \mathrm{mg}, 1.23 \mathrm{mmol})$ in $15 \mathrm{~mL}$ of a degassed $1: 1$ mixture of toluene and 1-butanol. The reaction followed by a work up yielded 9c as yellow solid (160 mg, 64\%).

${ }^{1} \mathrm{H}-\mathrm{NMR}:\left(500 \mathrm{MHz}, \mathrm{CD}_{2} \mathrm{Cl}_{2}\right.$ ): $\delta_{\mathrm{TMS}} 9.27$ (s, $\left.1 \mathrm{H}, \mathrm{ArH}\right), 9.12-8.90$ (br., 1H, ArH), 8.14 (t, 2H, ArH), 7.81-7.01 (br., 16H, ArH), 6.69-6.60 (br., $2 \mathrm{H}, \mathrm{ArH}$ ), 2.79 (t, 4H, $\mathrm{CH}_{2}-\mathrm{C}_{5} \mathrm{H}_{11}$ ), 1.57 (br., 8H, Alk- $\mathrm{C}_{6} \mathrm{H}_{13}$ ), 1.32

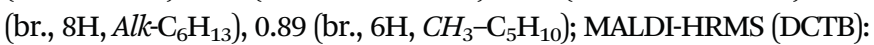
$m / z$ (\% int): $872.2800\left(\mathbf{M}^{\bullet+}, 100 \%\right),\left(m / z\right.$ calculated for $\mathrm{C}_{58} \mathrm{H}_{48} \mathrm{~S}_{4}$ 872.2639); UV/VIS: (toluene, $\left.10^{-5} \mathrm{M}\right), \lambda_{\max }[\mathrm{nm}]=299,326,373$.

2,2'-(6,9-Didodecyltribenzo[fg, $, j, r s t]$ pentaphene-3,12-diyl)bis(9-ethyl-9H-carbazole), 10a. 10a was prepared according to "method A" with 3,12-dibromo-6,9-didodecyltribenzo[ $f g, i j, r s t]$ pentaphene, 7 (150 mg, $0.17 \mathrm{mmol})$, 9-ethyl-9H-carbazole-3boronicacid pinacolester $(240 \mathrm{mg}, 0.75 \mathrm{mmol})$, tris(dibenzylideneacetone)dipalladium (0.015 g, $\left.1.7 \times 10^{-2} \mathrm{mmol}\right)$, Sphos (14 mg, $\left.3.4 \times 10^{-2} \mathrm{mmol}\right)$, and $\mathrm{K}_{3} \mathrm{PO}_{4}(160 \mathrm{mg}, 0.75 \mathrm{mmol})$ in 20 $\mathrm{mL}$ of a degassed 1:1 mixture of toluene and 1-butanol. The product was isolated as a yellow-brown solid (239 $\mathrm{mg}, 77 \%)$.

${ }^{1} \mathrm{H}-\mathrm{NMR}:\left(500 \mathrm{MHz}, \mathrm{CD}_{2} \mathrm{Cl}_{2}\right): \delta_{\mathrm{TMS}} 9.09$ (d, 2H, ArH), 8.858.60 (br., $4 \mathrm{H}, \mathrm{ArH}), 8.61$ (d, 2H, ArH), 8.26 (d, 2H, ArH), 8.117.74 (br., 4H, ArH), 7.75-6.60 (br., $12 \mathrm{H}, \mathrm{ArH}$ ), 4.42 (br., 4H, $\mathrm{CH}_{2}-\mathrm{CH}_{3}$ ), 3.15 (d, $4 \mathrm{H}, \mathrm{CH}_{2}-\mathrm{C}_{11} \mathrm{H}_{23}$ ), 1.97 (br., $6 \mathrm{H}, \mathrm{CH}_{3}-$ $\mathrm{C}_{11} \mathrm{H}_{22}$ ), 1.55-1.25 (br., 40H, Ar-alkyl), 0.84 (t, $6 \mathrm{H}, \mathrm{CH}_{2}-\mathrm{CH}_{3}$ ); MALDI-HRMS (DCTB): $\mathrm{m} / \mathrm{z}$ (\% int): 1098.6757 ( $\left.\mathbf{M}^{\bullet+}, 100 \%\right),(\mathrm{m} / \mathrm{z}$ calculated for $\mathrm{C}_{82} \mathrm{H}_{86} \mathrm{~N}_{2}$ 1098.6791); UV/VIS: (toluene, $10^{-5} \mathrm{M}$ ), $\lambda_{\max }[\mathrm{nm}]=299,353,372,403$.

3-(9,9-Dioctyl-9H-fluoren-2-yl)-12-(9,9-dioctyl-9H-fluoren-3-yl)6,9-didodecyltribenzo[fg, $\boldsymbol{j}$, rst $]$ pentaphene, $10 \mathrm{~b}$. $10 \mathrm{~b}$ was prepared according to "method A" using 3,12-dibromo-6,9-didodecyltribenzo[ $f g, i j, r s t]$ pentaphene, $7(150 \mathrm{mg}, \quad 0.17 \mathrm{mmol}), \quad 2-(9,9-$ dioctyl-9H-fluoren-2-yl)-4,4,5,5-tetramethyl-1,3,2-dioxaborolane (390 mg, $0.75 \mathrm{mmol}$ ), tris(dibenzylideneacetone)dipalladium (0.015 g, $\left.1.7 \times 10^{-2} \mathrm{mmol}\right)$, Sphos (14 mg, $\left.3.4 \times 10^{-2} \mathrm{mmol}\right)$, and $\mathrm{K}_{3} \mathrm{PO}_{4}(16 \mathrm{mg}, 0.75 \mathrm{mmol})$ in $15 \mathrm{~mL}$ of a degassed $1: 1$ mixture of toluene and 1-butanol. The reaction followed by a work up yielded $10 \mathrm{~b}$ as a brown solid (325 $\mathrm{mg}, 78 \%)$.

${ }^{1} \mathrm{H}-\mathrm{NMR}:\left(500 \mathrm{MHz}, \mathrm{CD}_{2} \mathrm{Cl}_{2}\right): \delta_{\mathrm{TMS}} 7.79(\mathrm{t}, 2 \mathrm{H}, \mathrm{ArH}), 7.65$ (t, 4H, ArH), 7.48 (t, 2H, ArH). 7.33 (br., 2H, ArH), 7.25-7.12 (m, 12H, ArH), 6.71 (d, 4H, ArH), 2.41 (m, 4H, Alkyl), 2.12-1.62 (54H, Alkyl), 1.38-1.26 (54H, Alkyl), 0.88 (6H, Alkyl); MALDIHRMS (DCTB): $m / z$ (\% int): $1490.1961\left(\mathbf{M}^{\bullet+}, 100 \%\right),(m / z$ calculated for $\mathrm{C}_{112} \mathrm{H}_{144}$ 1490.1302); UV/VIS: (toluene, $10^{-5} \mathrm{M}$ ), $\lambda_{\max }[\mathrm{nm}]=308$, $326,373$.

$5^{\prime}, 5^{\prime \prime}$-(6,9-Didodecyltribenzo[fg, $\boldsymbol{j}$, ,rst $]$ pentaphene-3,12-diyl)bis(5hexyl-2,2'-bithiophene), 10c. 10c was prepared according to "method A" using 3,12-dibromo-6,9-didodecyltribenzo[ $f g, i j, r s t]$ pentaphene, 7 (150 mg, $0.17 \mathrm{mmol}), 5^{\prime}$-Hexyl-2,2'-bithiophene5-boronicacid pinacolester $(0.280 \mathrm{~g}, 0.28 \mathrm{mmol})$, tris(dibenzylideneacetone)dipalladium $\left(0.015 \mathrm{~g}, 1.7 \times 10^{-2} \mathrm{mmol}\right)$, Sphos (14 mg, $\left.3.4 \times 10^{-2} \mathrm{mmol}\right)$ and $\mathrm{K}_{3} \mathrm{PO}_{4}(160 \mathrm{mg}, 0.75 \mathrm{mmol})$ in $15 \mathrm{~mL}$ of a degassed 1:1 mixture of toluene and 1-butanol. The reaction followed by a work up yielded $\mathbf{9 b}$ as a brown solid (229 mg, 67\%). 
${ }^{1} \mathrm{H}-\mathrm{NMR}$ : (500 MHz, $\mathrm{CD}_{2} \mathrm{Cl}_{2}$ ): $\delta_{\text {TMS }} 9.11-8.78$ (br., $\left.6 \mathrm{H}, \mathrm{ArH}\right)$, 7.95-7.38 (br., 6H, ArH), 7.34 (p, 2H, ArH), 7.19-7.00 (br., 4H, ArH), 6.76 (s, 1H, ArH), 6.61 (d, 1H, ArH), 3.18 (d, 4H, Alk$\mathrm{C}_{6} \mathrm{H}_{13}$ ), 2.84 (br., $4 \mathrm{H}$, Alk- $\mathrm{C}_{6} \mathrm{H}_{13}$ ), 1.99-0.85 (br., $60 \mathrm{H}$, Alk- $\mathrm{C}_{6} \mathrm{H}_{13}$ and Ar-Alk); MALDI-HRMS (DCTB): $m / z$ (\% int): $1208.6406\left(\mathrm{M}^{\bullet+}\right.$, $100 \%),\left(\mathrm{m} / z\right.$ calculated for $\mathrm{C}_{82} \mathrm{H}_{96} \mathrm{~S}_{4}$ 1208.6395); UV/VIS: (toluene, $10^{-5} \mathrm{M}$ ), $\lambda_{\max }[\mathrm{nm}]=300,409,432$.

5,10-Bis(9-ethyl-9H-carbazol-2-yl)tribenzo[ $f g, i j, r s t]$ pentaphene, 11a. 11a was prepared according to "method A" with 5,10dibromotribenzo[fg, $i j, r s t]$ pentaphene, $8(125 \mathrm{mg}, 0.23 \mathrm{mmol})$, 9-ethyl-9H-carbazole-3-boronicacid pinacolester $(300 \mathrm{mg}, 0.93 \mathrm{mmol}$ ), tris(dibenzylideneacetone)dipalladium $\left(10 \mathrm{mg}, 1.1 \times 10^{-2} \mathrm{mmol}\right)$, Sphos (10 mg, $2.3 \times 10^{-2} \mathrm{mmol}$ ), and $\mathrm{K}_{3} \mathrm{PO}_{4}(12 \mathrm{mg}, 0.58 \mathrm{mmol})$ in $20 \mathrm{~mL}$ of a degassed 1:1 mixture of toluene and 1-butanol. The desired product was isolated as an orange solid (90 mg, 50\%).

${ }^{1} \mathrm{H}-\mathrm{NMR}$ : (500 MHz, $\mathrm{CD}_{2} \mathrm{Cl}_{2}$ ): $\delta_{\mathrm{TMS}} 9.24$ (s, 2H, $\left.\mathrm{ArH}\right), 9.11(\mathrm{~d}$, $2 \mathrm{H}, \mathrm{ArH}), 9.02$ (d, 2H, ArH), 8.97 (d, 2H, ArH), 8.90 (d, 2H, ArH), 8.13 (t, 4H, ArH), 7.81 (p, 4H, ArH), 7.53 (p, 4H, ArH), 7.57-7.25 (br., 6H, ArH), 4.47 (q, $4 \mathrm{H}, \mathrm{CH}_{2}-\mathrm{CH}_{3}$ ), 1.51 (t, $6 \mathrm{H}, \mathrm{CH}_{2}-\mathrm{CH}_{3}$ ); ${ }^{13} \mathrm{C}-\mathrm{NMR}$ : (90.55 MHz, $\mathrm{CD}_{2} \mathrm{Cl}_{2}$ ); MALDI-HRMS (DCTB): $\mathrm{m} / \mathrm{z}(\%$ int): $762.3034\left(\mathrm{M}^{\bullet+}, 100 \%\right),\left(\mathrm{m} / \mathrm{z}\right.$ calculated for $\mathrm{C}_{58} \mathrm{H}_{38} \mathrm{~N}_{2}$ 762.3030); UV/VIS: (toluene, $\left.10^{-5} \mathrm{M}\right), \lambda_{\max }[\mathrm{nm}]=311,350,369$.

5-(9,9-Dioctyl-9H-fluoren-2-yl)-10-(9,9-dioctyl-9H-fluoren-3-yl)tribenzo[ $f \boldsymbol{g}, \boldsymbol{j}, \boldsymbol{r s t}]$ pentaphene, 11b. 11b was prepared using "method A" using 5,10-dibromotribenzo[ $f g, i j, r s t]$ pentaphene, 8 (300 mg, $0.56 \mathrm{mmol}$ ), 2-(9,9-dioctyl-9H-fluoren-2-yl)-4,4,5,5tetramethyl-1,3,2-dioxaborolane (1.160 g, $2.24 \mathrm{mmol}$ ), tris(dibenzylideneacetone)dipalladium (51 mg, $5.6 \times 10^{-2} \mathrm{mmol}$ ), Sphos (46 mg, $\left.1.1 \times 10^{-2} \mathrm{mmol}\right)$ and $\mathrm{K}_{3} \mathrm{PO}_{4}(476 \mathrm{mg}, 2.24 \mathrm{mmol})$ in $20 \mathrm{~mL}$ of a degassed 1:1 mixture of toluene and 1-butanol. The reaction followed by a work up yielded $11 \mathrm{~b}$ as an orange solid (450 mg, 69\%).

${ }^{1} \mathrm{H}-\mathrm{NMR}$ : $\left(500 \mathrm{MHz}, \mathrm{CD}_{2} \mathrm{Cl}_{2}\right.$ ): $\delta_{\mathrm{TMS}} 9.10(\mathrm{~d}, 2 \mathrm{H}, \mathrm{ArH}), 8.96-$ 8.75 (br., $4 \mathrm{H}, \mathrm{ArH}), 8.01$ (t, 2H, ArH), 7.90 (d, 2H, ArH), 7.81 (d, $2 \mathrm{H}, \mathrm{ArH}), 7.79-7.77$ (d, 2H, ArH), 7.62 (d, 2H, ArH), $7.53(\mathrm{t}, 2 \mathrm{H}$, ArH), 7.39-7.10 (br., 8H, ArH), 7.06 (t, 2H, ArH), 2.18-1.80 (br. 8H, Alkyl), 1.30-0.55 (br., 60H, Alkyl); ${ }^{13} \mathrm{C}-\mathrm{NMR}$ : (90.55 MHz, $\mathrm{CD}_{2} \mathrm{Cl}_{2}$ ): $\delta_{\mathrm{TMS}} 152.15$ (2C, $\left.\mathrm{Ar}\right), 151.61$ (2C, $\left.\mathrm{Ar}\right), 144.89$ (2C, $\mathrm{Ar}$ ), 141.41 (2C, Ar), 140.41 (2C, Ar), 140.14 (2C, Ar), 131.84-130.39 (5C, Ar), 128.08-127.35 (8C, Ar), 125.74 (2C, Ar), 124.90-123.50 (9C, Ar), 122.27-120.24 (12C, Ar), 40.97-40.79 (4C, Alkyl), 32.4932.36 (4C, Alkyl), 30.44-29.69 (8C, Alkyl), 24.51-23.11 (12C, Alkyl), 14.39 (4C, Alkyl); MALDI-HRMS (DCTB): $m / z$ (\% int): 1152.7524 $\left(\mathrm{M}^{\bullet+}, 100 \%\right),\left(\mathrm{m} / \mathrm{z}\right.$ calculated for $\mathrm{C}_{88} \mathrm{H}_{96}$ 1152.7512); UV/VIS: (toluene, $10^{-5} \mathrm{M}$ ), $\lambda_{\max }[\mathrm{nm}]=302,352,368$.

5,10-Bis(5'-hexyl-2,2'-bithiophen-5-yl)tribenzo[ $f g, i j$, ,rst $]$ pentaphene, 11c. 11c was prepared according to "method A" using 5,10-dibromotribenzo[fg, $i j, r s t]$ pentaphene, 8 (200 mg, $0.37 \mathrm{mmol})$, 5'-Hexyl-2,2'-bithiophene-5-boronicacid pinacolester $(710 \mathrm{mg}$, $1.8 \mathrm{mmol}$ ), tris(dibenzylideneacetone)dipalladium (17 mg, $1.8 \times$ $10^{-2} \mathrm{mmol}$ ), Sphos (15 mg, $\left.3.7 \times 10^{-2} \mathrm{mmol}\right)$ and $\mathrm{K}_{3} \mathrm{PO}_{4}(200 \mathrm{mg}$, $0.94 \mathrm{mmol}$ ) in $20 \mathrm{~mL}$ of a degassed $1: 1$ mixture of toluene and 1-butanol. The reaction followed by a work up yielded $11 \mathrm{c}$ as a yellow solid (175 mg, 53\%).

${ }^{1} \mathrm{H}-\mathrm{NMR}$ : $\left(500 \mathrm{MHz}, \mathrm{CD}_{2} \mathrm{Cl}_{2}\right.$ ): $\delta_{\mathrm{TMS}} 9.27$ (s, 2H, ArH), 9.148.94 (6H, ArH), 8.17 (p, 2H, ArH), 7.85(p, 4H, ArH), 7.29-7.09 (8H, ArH), 1.64 (br., 20H, Alk- $\mathrm{C}_{6} \mathrm{H}_{13}$ ), 0.95 (t, 6H, $\mathrm{CH}_{3}-\mathrm{C}_{5} \mathrm{H}_{10}$ );
MALDI-HRMS (DCTB): $\mathrm{m} / \mathrm{z}$ (\% int): $872.2622\left(\mathrm{M}^{\bullet+}, 100 \%\right),(\mathrm{m} / \mathrm{z}$ calculated for $\mathrm{C}_{58} \mathrm{H}_{48} \mathrm{~S}_{4}$ 872.2639); UV/VIS: (toluene, $10^{-5} \mathrm{M}$ ), $\lambda_{\text {max }}[\mathrm{nm}]=302,352,369$.

\section{Acknowledgements}

The project was partially supported by Kuwait Foundation for the Advancement of Sciences (KFAS) under project code: 20131506-01. BA and FS acknowledge the general facilities projects GS01/03, GS03/01, and GS03/08 at Kuwait University.

\section{Notes and references}

1 C. Wang, H. Dong, W. Hu, Y. Liu and D. Zhu, Chem. Rev., 2012, 112, 2208-2267.

2 (a) M. Ball, Y. Zhong, Y. Wu, C. Schenck, F. Ng, M. Steigerwald, S. Xiao and C. Nuckolls, Acc. Chem. Res., 2015, 48, 267-276; (b) U. Zschieschang, H. Klauk, I. B. Müeller, A. J. Strudwick, T. Hintermann, M. G. Schwab, A. Narita, X. Feng, K. Müllen and R. T. Weitz, Adv. Electron. Mater., 2015, 1400010, DOI: 10.1002/ aelm.201400010; (c) A. Bashir, A. Heck, A. Narita, X. Feng, A. Nefedov, M. Rohwerder, K. Mullen, M. Elstnerb and C. Woll, Phys. Chem. Chem. Phys., 2015, 17, 21988-21996; (d) Z. Sun, Q. Ye, C. Chi and J. Wu, Chem. Soc. Rev., 2012, 41, 7857-7889; (e) A. Konishi, Y. Hirao, K. Matsumoto, H. Kurata, R. Kishi, Y. Shigeta, M. Nakano, K. Tokunaga, K. Kamada and T. Kubo, J. Am. Chem. Soc., 2013, 135, 1430-1437; $(f)$ X. Yan and L.-s. Li, J. Mater. Chem., 2011, 21, 3295-3300.

3 A. Narita, X.-Y. Wang, X. Feng and K. Muellen, Chem. Soc. Rev., 2015, 44, 6616-6643.

4 (a) R. Berger, A. Giannakopoulos, P. Ravat, M. Wagner, D. Beljonne, X. Feng and K. Mullen, Angew. Chem., Int. Ed., 2014, 53, 10520-10524; (b) C. J. Martin, B. Gil, S. D. Perera and S. M. Draper, Chem. Commun., 2011, 47, 3616-3618; (c) T. Hatakeyama, S. Hashimoto and M. Nakamura, Org. Lett., 2011, 13, 2130-2133.

5 (a) S. Ito, Y. Tokimaru and K. Nozaki, Angew. Chem., Int. Ed., 2015, 54, 1-5; (b) J. Luo, X. Xu, R. Mao and Q. Miao, J. Am. Chem. Soc., 2012, 134, 13796-13803.

6 (a) Q. Zhang, H. Peng, G. Zhang, Q. Lu, J. Chang, Y. Dong, X. Shi and J. Wei, J. Am. Chem. Soc., 2014, 136; (b) B. Schuler, S. Collazos, L. Gross, G. Meyer, D. Pérez, E. Guitián and D. Peña, Angew. Chem., Int. Ed., 2014, 126, 9150-9152.

7 M. G. Debije, J. Piris, M. P. De Haas, J. M. Warman, Z. Tomovic, C. D. Simpson, M. D. Watson and K. Müllen, J. Am. Chem. Soc., 2004, 126, 4641-4645.

8 (a) B. Alameddine, A. H. Rice, C. Luscombe and T. A. Jenny, ChemistryOpen, 2015, 4, 453-456; (b) H. Huang, C.-E. Chou, Y. Che, L. Li, C. Wang, X. Yang, Z. Peng and L. Zang, J. Am. Chem. Soc., 2013, 135, 16490-16496; (c) C.-E. Chou, Y. Li, Y. Che, L. Zang and Z. Peng, RSC Adv., 2013, 3, 20666-20672; (d) B. Alameddine, M. Schindler, S. Martin-Caba and T. A. Jenny, Synthesis, 2012, 44, 1928-1934. 
9 (a) K. E. Maly, E. Gagnon, T. Maris and J. D. Wuest, J. Am. Chem. Soc., 2007, 129, 4306-4322; (b) G. Vives and G. Rapenne, Tetrahedron Lett., 2006, 47, 8741-8744; (c) S. Watanabe and J. Kido, Chem. Lett., 2007, 36, 590-591.

10 G. Xu, J. Zhao, C. Cui, Y. Hou and Y. Kong, Electrochim. Acta, 2013, 112, 95-103.

11 H. Zaugg, R. T. Rapala and M. T. Leffler, J. Am. Chem. Soc., 1948, 70, 3224-3228.
12 L. A. Paquette, R. E. Moerck, B. Harirchian and P. D. Magnus, J. Am. Chem. Soc., 1978, 100, 1597-1599.

13 N. Miyaura, T. Yanagai and A. Suzuki, Synth. Commun., 1981, 11, 513.

14 T. E. Barder, S. D. Walker, J. R. Martinelli and S. L. Buchwald, J. Am. Chem. Soc., 2005, 127, 4685-4696.

15 P. Kovacic and F. W. Koch, J. Org. Chem., 1963, 28, 1864-1867. 